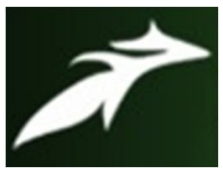

Gadona Enoch Alhamdu et al, International Journal of Advances in Agricultural Science and Technology,

Vol.7 Issue.11, November-2020, pg. 123-131

ISSN: 2348-1358

Impact Factor: 6.057

NAAS Rating: 3.77

\title{
ANALYSIS OF LAND DEGRADATION IN GANYE LOCAL GOVERNMENT OF ADAMAWA STATE, NIGERIA
}

\author{
Gadona Enoch Alhamdu ${ }^{1}$; Gamaniel Japheth ${ }^{2}$; Umaru Buba Alim³ \\ Federal Polytechnic Mubi, School of Environmental Science, Department of Surveying and Geoinformatics, NIGERIA \\ DOI: 10.47856/ijaast.2020.v07i11.016
}

\begin{abstract}
Land degradation is the consequence of important processes active in arid and semi-arid ecosystem, where water is the original limiting factor in execution of land practice and management. The research study identified and mapped degraded areas in Ganye local government from the land use and land cover maps of 1986, 1996, 2006 and 2016 (Landsat ETM). Satellite images were processed and classified into five different land use classes. Extend of area coverage of degraded areas were obtained from the land use land cover classification. The result obtained showed the area extend of degradation, agricultural lands continued to expand, urban/built up areas continue to increase. The rich vegetation cover continued to decline as a result of anthropogenic activities. The water surfaces area decline as a result of draught and erratic rainfall, while bare surface areas continued to increase which shows that land is being degraded. It recommends campaign awareness to discourage bush burning and planting of cover crops.
\end{abstract}

Keywords: Degradation, Extend area, satellite images

\section{Introduction}

Land Degradation Assessment in Dry lands (LADA) defines land degradation as the long term reduction in the capacity of land to perform ecosystem function and service (including those of agro-ecosystem function and urban systems)

This needs to follow a globally structured approach, based on adequate, reliable, up-todate and knowledge governed by appropriate strategies and agreements. One key product sorely lacking to reach this goal is an overview of where land degradation takes place at what intensity and how land users are addressing this problem through

According to Land Degradation Assessment in Dry Lands (LADA, 2013) sustainable management of the natural resource base is one of a very few, truly fundamental issues that the international community will be obliged to address effectively over the next two decades

This needs to follow a globally structured approach, based on adequate, reliable, up-todate and knowledge governed by appropriate strategies and agreements. One key product sorely lacking to reach this goal is an overview of where land degradation takes place at what intensity 


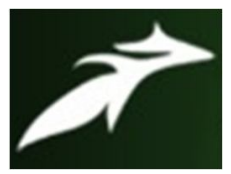

Gadona Enoch Alhamdu et al, International Journal of Advances in Agricultural Science and Technology,

Vol.7 Issue.11, November-2020, pg. 123-131

ISSN: 2348-1358

Impact Factor: 6.057

NAAS Rating: 3.77

and how land users are addressing this problem through sustainable land management (Hanspeter, Godert, Freddy and Gudru, 2008).

, Land degradation is caused by a variety of complex interrelated degradation process; these can be grouped into four (4) major land degradation types, each of which can be subdivided according to specific subset of degradation process.

i. Soil degradation

ii. Vegetation degradation

iii. Water resource degradation

iv. Soil or water pollution (Ann, 2002)

A major short coming of land degradation assessment is the lack of cause effect relationship between severity of degradation and productivity criteria for designing different classes of land degradation (e.g. low, medium, high and others) are generally based on properties rather than their impact on productivity (Blessing, Chukwudumeli, Yusuf and Victoria, 2011) carried out research study on farmers perception of climate change and adaptation strategies in Northern Nigeria. This was an empirical assessment, to look at the causes, constraints and strategies towards effective climate change in Northern Nigeria

Land degradation is the decline in productive capacity of the land. This in fact is the main reason for the dramatic decrease of prime lands where only $3 \%$ of the global surface is left prime (Eswaran, Lai, and Reich, 2001). Land degradation, causing the loss of productivity potential, receives a wide area of concern globally due to its significant negative impacts on production(Barrow 1994)affirmed land degradation causing productivity decline at an alarming rate,

There is that dearth of information between land covert types and natural phenomenon such as rainfall and other climatic conditions. While these information's exist, on the presences of anthropogenic activities, main drivers of land degradation and the underlying factors that drive this degradation are lacking. This lack of information implies that whatever programs that are put in place for sustainable use of resource as on soil degradation in Ganye local government would not yield the desired result.

The research study is aimed at determining the extend of area coverage of degraded lands in Ganye local government, which is derived from the land use land cover maps of 1986,1996,2006 and2016 time period with the view of assessing the extend of degraded areas and providing necessary information for sustainable land management in the area. 


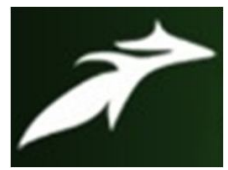

Gadona Enoch Alhamdu et al, International Journal of Advances in Agricultural Science and Technology,

Vol.7 Issue.11, November-2020, pg. 123-131

ISSN: 2348-1358

Impact Factor: 6.057

NAAS Rating: 3.77

\section{Study Area}

The research study covers Ganye local government area in Adamawa state located in the southern guinea savannah zone. The area is covered by latitude $8^{\circ} 15^{\prime}$ and $8^{\circ} 45^{\prime} \mathrm{N}$ and longitude $11^{\circ} 10^{\prime}$ and $12^{\circ} 45^{\prime} \mathrm{E}$

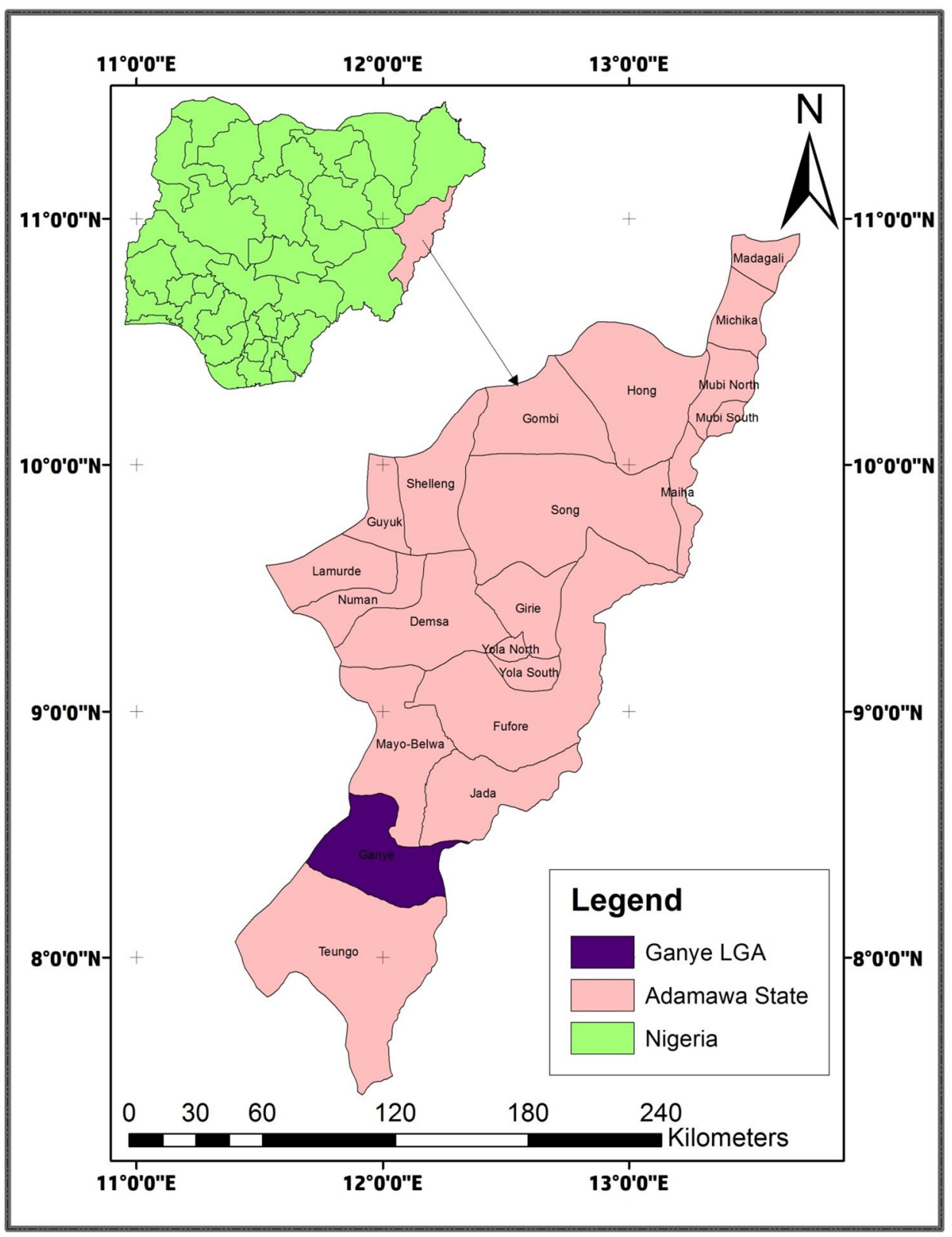

Figure 1A: Map of Adamawa Showing the Study Area. 


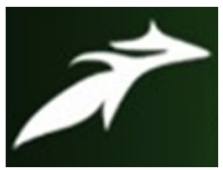

Gadona Enoch Alhamdu et al, International Journal of Advances in Agricultural Science and Technology,

Vol.7 Issue.11, November-2020, pg. 123-131

ISSN: 2348-1358

Impact Factor: 6.057

NAAS Rating: 3.77

\section{Methodology}

\section{Equipment's, Hardware and Software}

\section{Hardware}

i. Global Positioning System (GPS) 10 hand held series (2011-2012)>3

ii. Digital Camera Cannon Power short A2300

iii. Laptop Computer Pentium 1v processorHDD100GB and 2.7 Ghram Memories

iv. Hp color and black, inkjet advantage 1575 Desk jet printer, scanner and Copier.

v. External Hard Drive 500GB

\section{Software}

ITC International Land and Water Information System (ILWIS 3.1)

i. $\quad$ ESRI Arc Geographic Information System Arc GIS 10.3

ii. Leicas Earth Resource Data Analysis System (ERDAS) imagine 2014

iii. $\quad 2007$ Microsoft word, Microsoft Excel and graphic application

\section{Identification of Degraded Areas}

\section{Field Survey}

The study involved field survey, and this aided in the collection of data that were not covered by the questionnaires. The field survey involved inventory of latitude and longitude of location of the degraded sites, this degraded sites include; Flood prone areas, Gully erosion sites, Depleted vegetation areas, Bare surface areas, this include rock outcrops. Their locations were identified and captured using the handheld GPS and were mapped.

\section{Mapping Degraded Areas}

The first step in mapping the degraded areas was to look at the land use and land cover map of the study area from 1986 to 2016. The degraded areas were first identified and classified as: Depleted Vegetation, Gully erosion, Flood prone areas, bare soil and Water surface area. The locations of the various degraded areas were captured using the handheld GPS. The coordinates assisted in determining the approximate positions of the degraded areas, which were plotted on 


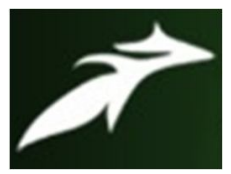

Gadona Enoch Alhamdu et al, International Journal of Advances in Agricultural Science and Technology,

Vol.7 Issue.11, November-2020, pg. 123-131

ISSN: 2348-1358

Impact Factor: 6.057

NAAS Rating: 3.77

the map. Depleted vegetation was identified as areas with few plants with lower density. Reduction in vegetation ground cover that was formerly a vegetated area. Adverse changes in the quality and quantity of plants that are found in grassland, forested and woodland (Ann, 2012) other areas were identified as a result of human activities; farmland, bush burning, fuel for wood, these activities reduce vegetation cover.

\section{Results and Discussions}
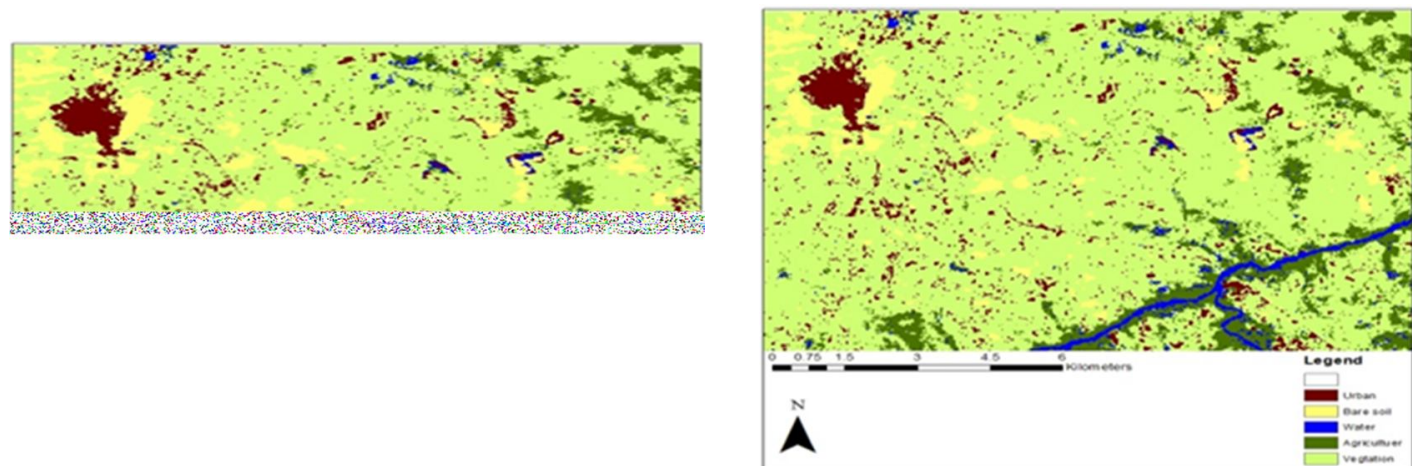

Figure1: Land Use Land Cover of Ganye 1986 Source: Landsat ETM downloaded from Earth Figure 2: Land Use Land Cover of Ganye 1996 Source: Landsat ETM downloaded from Earth Explorer Explorer

Figures 1 and 2 shows the land use land cover classification of Ganye for 1986 and 1996.The land use land cover were classified into five different land cover classes, vegetation, agricultural lands, urban areas, water surface and bare surface areas.

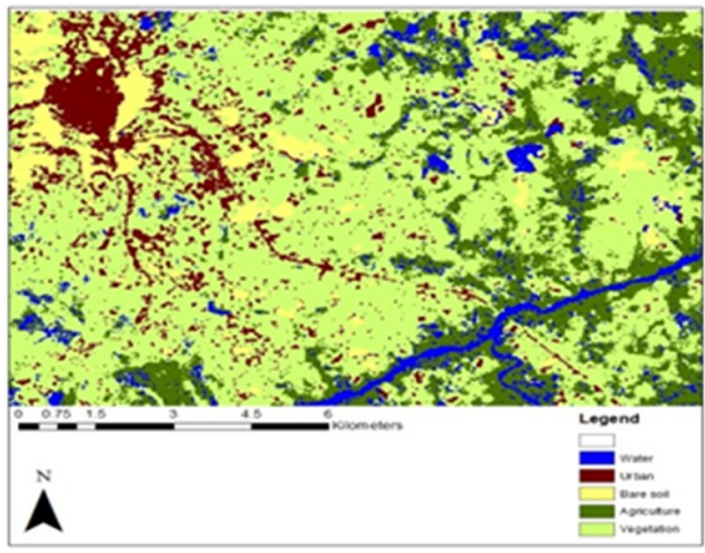

Figure 3: Land Use Land Cover of Ganye 2006 Source: Landsat ETM downloaded from Earth Explorer

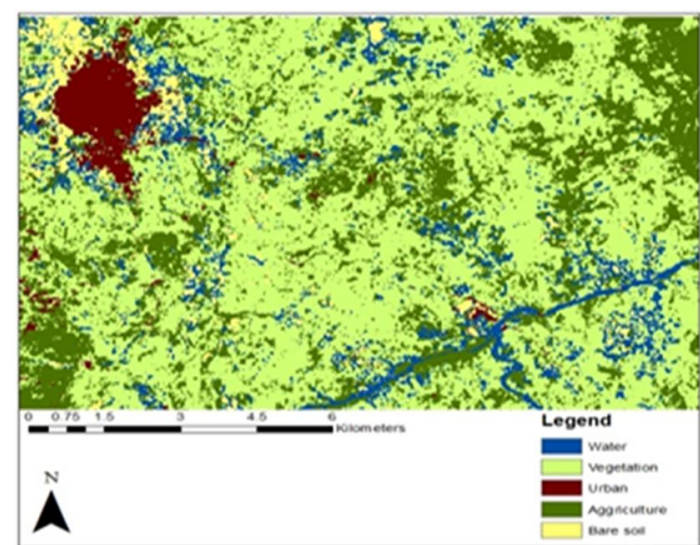

Figure 4: Land Use Land Cover of Ganye 2016 Source: Landsat ETM downloaded from Earth Explorer 


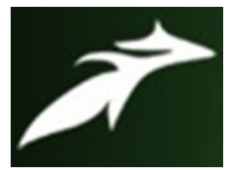

Gadona Enoch Alhamdu et al, International Journal of Advances in Agricultural Science and Technology,

Vol.7 Issue.11, November-2020, pg. 123-131

ISSN: 2348-1358

Impact Factor: 6.057

NAAS Rating: 3.77

Figures 3 and 4 shows the land use land cover classification of Ganye for 2006 and 2016.The land use land cover were classified into five different land cover classes, vegetation, agricultural lands, urban areas, water surface and bare surface areas.

Figure 5 shows the DEM of Ganye, the western part have an elevation of $1067 \mathrm{~m}$ while the eastern part has $300 \mathrm{~m}$. because of this height difference erosion site are common down the steep slope areas

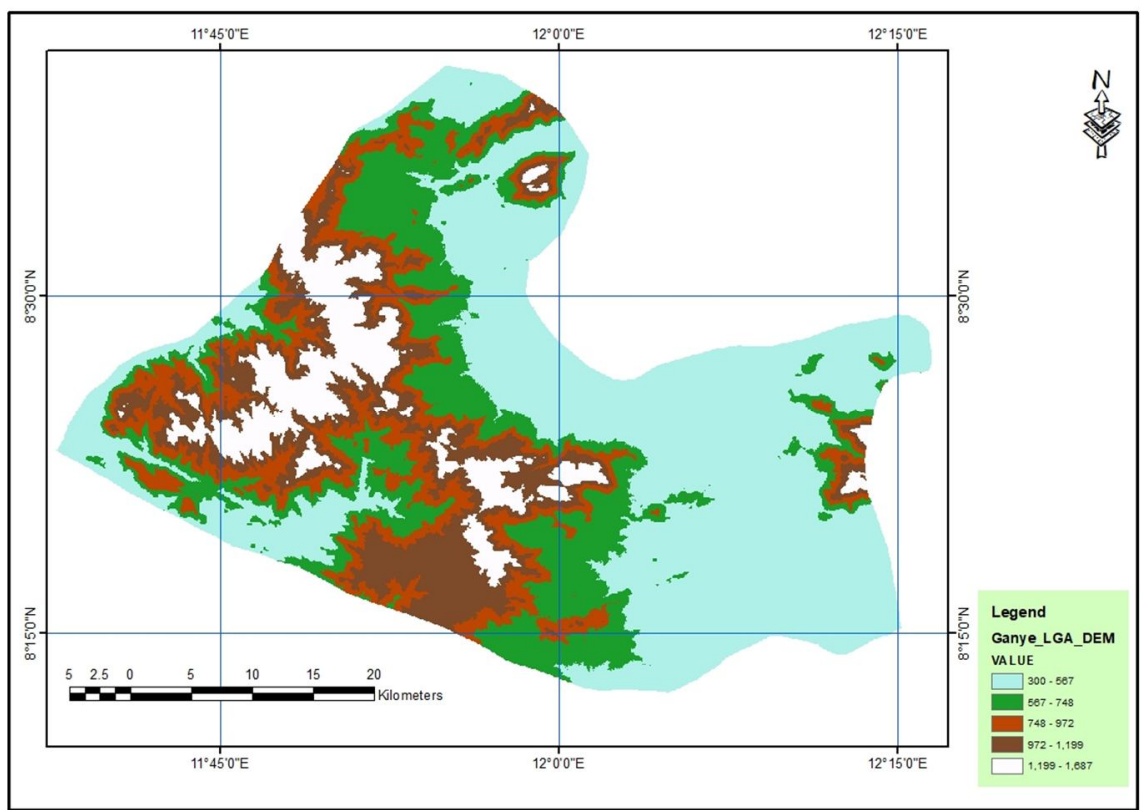

Figure 5: Digital Elevation Model of Ganye

Source: Downloaded from (ASTER-GDEM) 


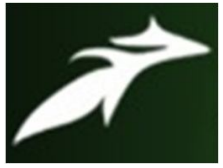

Gadona Enoch Alhamdu et al, International Journal of Advances in Agricultural Science and Technology,

Vol.7 Issue.11, November-2020, pg. 123-131

ISSN: 2348-1358

Impact Factor: 6.057

NAAS Rating: 3.77

Table 1: Extend of Area Coverage in Square Killometers, Ganye L.Govt

\begin{tabular}{lllllll} 
Period & \multicolumn{2}{l}{ Total Land Agriculture } & Vegetation & Urban Area Bare Soil & Water \\
& Area & & & & & \\
& & & & & & \\
1986 & 167,582 & 17521 & 123329 & 9031 & 8090 & 11657 \\
1996 & 167,582 & 47367 & 94190 & 10447 & 8599 & 9025 \\
2006 & 167,582 & 17571 & 103329 & 18567 & 21447 & 8714 \\
2016 & 167,582 & 17681 & 103341 & 18555 & 22561 & 7490
\end{tabular}

\section{Ganye Local Government}

Five land use classes were identified for 1986, 1996.2006.and 2016: Agriculture, Vegetation, Urban area, bare soil and Water surface.

Agricultural activities recorded an increase between 1986 to1996 from $17521 \mathrm{sqkm}$ to 33344sqkm and decline between 1996 and 2006 from 33344sqkm to 17571sqkm and rise in 2006 from 17571 sqkm to 179,314 sqkm in 2006.

Vegetation decline between the years 1986 to 1996 from 123,329sqkm to 94,190sqkm, and increases between 1996 to 2006 from 94190 to 103,329sqkm and rise again in 2016 to 361,700 sqkm.

Urban area increases between the years 1986 to 1996 from $9031 \mathrm{sqkm}$ to $10,3447 \mathrm{sqkm}$ and continue to rise in 2006 from 10,447sqkm to $18,567 \mathrm{sqkm}$ and continue to rise in 2016 to 23,109 sqkm. 


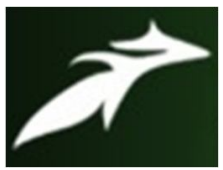

Gadona Enoch Alhamdu et al, International Journal of Advances in Agricultural Science and Technology,

Vol.7 Issue.11, November-2020, pg. 123-131

ISSN: 2348-1358

Impact Factor: 6.057

NAAS Rating: 3.77

\section{Findings}

The increase in agricultural activities and urban expansion resulted in decrease in vegetation cover, thus conversion of vegetation land to agriculture and urban areas as a result of population growth.

Findings revealed that the massive clearance of vegetation cover and rapid urban growth resulted in decline in vegetation cover as a result of human activities on vegetation. While bare soil increase as a result of decline in water surface as a result of draught and erratic rain fall pattern recorded in the area during the period of study.

The total land area in 1986 was $167,582 \mathrm{sqkm}$ and continued to increase to $594,813 \mathrm{sqkm}$ in 2016 . This was as a result of increase in agricultural and urban areas resulting to decline in vegetation cover; this is attributed to human activities. There was increase in bare soil in 2006 and 2016 as a result of decline in water surface resulting from erratic rainfall and draught experienced in the area.

\section{Summary and Conclusion}

In determining extend of area coverage of the degraded areas, the land use and land cover maps of 1986, 1996, 2006 and 2016 were used. The satellite images (Landsat ETM) were processed using International Land and Water Information System (ILWIS 3.1) and ArcGIS 10.3 with ERDAS Imagine 2014. The satellite images were subset base on the area of interest, image classification was achieved using Image differencing method. Supervised image classification was carried out and images were classified into five different classes; agricultural areas, built up areas, vegetation, bare surface areas and water surface area.

It is clear from the study that land degradation is often a function of the socioeconomic characteristics of the population. For example, agricultural expansion and built up areas were in the increase, thus the natural vegetation, clearance is attributed to land shrinkages for urban development and agricultural activities. Results from this study have demonstrated the need for an all-inclusive methodology for mapping and analysing degraded land 


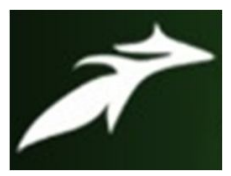

Gadona Enoch Alhamdu et al, International Journal of Advances in Agricultural Science and Technology,

Vol.7 Issue.11, November-2020, pg. 123-131

ISSN: 2348-1358

Impact Factor: 6.057

NAAS Rating: 3.77

\section{REFERENCES}

[1]. Ann, V. D. (2010). Soil Degradation: international Center for erotology. Universities Gent

[2]. Barrow C J (1994). Land degradation: development and breakdown of terrestrial environment: Cambridge university press, great Britain pp. 295

[3]. Blessing,K.F, Chukwudumebi,L.E, Yusuf,L.I and Victoria C Agu(2011) Farmers Perceptions of Climate Change and Adaptation Strategies in Northern Nigeria: An Empirical Assessment

[4]. Eswaram, H. Lai, R. and Reichi, P. F. (2001). Land Degradation. An overview in Second International Conference on Land Degradation and Desertification (Sdr) E.M. Bridges; I.D. Aannan; I.R, Oldeman; F.W.T. Penm. Devries and S. Sampatparit. Oxford press, Kchom Kaem. Thailand.

[5]. Hanspeter L; Goder vcan Lynden; FreddyN. And Gudrums (2008). A questionnaire for mapping land degradation and sustainable land management. World overview of conservation approaches and technologies (WOCAT) Vol. pp IV -V.

[6]. LADA(2013) land Degradation Assessment in Dry Lands: questionnaire for mapping land degradation and sustainable land management: FAO 2013. 